\title{
DIAGNÓSTICO DO ESTADO GEOAMBIENTAL DA ÁREA URBANA DO MUNICÍPIO DE CUBATÃO (SP)
}

\author{
Geoenvironmental conditions diagnosis of the urban area of Cubatão, \\ São Paulo, Brazil
}

Leandro de Godoi Pinton

Universidade Estadual Paulista - UNESP, Rio Claro, São Paulo, Brasil

lgpgeo@yahoo.com.br

Cenira Maria Lupinacci da Cunha

Universidade Estadual Paulista - UNESP, Rio Claro, São Paulo, Brasil

cenira@rc.unesp.br

Artigo recebido em 06/11/2013 e aceito para publicação em 05/03/2014.

RESUMO: A degradação das paisagens que envolvem a área urbana do município de Cubatão (SP) é proveniente de organizações espaciais delineadas por transformações socioeconômicas seculares, especialmente pelo modelo de urbanização instaurado a partir da segunda metade do século XX. Neste contexto, a obtenção de dados sobre a capacidade de regulação das funções geoecológicas das paisagens segundo o grau de intervenção antrópica em seus componentes naturais se constitui em instrumento de auxílio ao planejamento ambiental. Assim, o presente artigo teve como objetivo discutir o diagnóstico do estado geoambiental das paisagens da área urbana do município de Cubatão (SP), executado a partir do uso da proposta metodológica da Geoecologia da Paisagem, na escala 1:10.000. A pesquisa teve como respaldo metodológico os princípios que concernem à Teoria Geral dos Sistemas. A análise do diagnóstico, desenvolvida a partir da avaliação de dados representados em documento cartográfico específico, possibilitou a identificação de problemas ambientais vinculados à violação da legislação ambiental e rompimento da capacidade de uso potencial das paisagens da área de estudo.

Palavras Chave: Sistema ambiental litorâneo, Geoecologia da paisagem, Estado geoambiental, Planejamento ambiental, Geomorfologia.

ABSTRACT: The degradation of landscapes which involves the urban area of Cubatão city (SP) is derived from spatial organizations outlined sócio-economic transformations over the last centuries, especially by an urbanization model established since the second half of the 20th century. In such context, obtaining data on regulating capacity of the landscapes' geocological functions according to the anthropic intervention degree in its natural components constitutes as an aid instrument to the environmental planning. Thus, this study aimed to discuss the geoenvironmental conditions diagnosis of the landscapes from the urban area of Cubatão city (SP), carried out through the methodology proposed by Geoecology on scale of 1:10.000. The research was supported by the methodological principles of the General Systems Theory. The analysis of the diagnosis, developed from the assessment of data represented in particular cartographic document, allowed the identification of environmental problems related to the breach of environmental regulations and rupture of use potencial capacity of the studied area landscapes.

Key words: Coastal environmental system, Geoecology, Geoenvironmental conditions, Environmental planning, Geomorphology. 


\section{INTRODUÇÃO}

As áreas litorâneas do Brasil são caracterizadas por elevado nível de degradação ambiental decorrente de organizações espaciais delineadas pelas transformações socioeconômicas seculares. O sistema ambiental litorâneo que envolve a área urbana do município de Cubatão (SP) se insere neste contexto, já que se constitui em área de povoamento pioneiro do Brasil e, a partir da segunda metade do século XX, o modelo de atividades econômicas essencialmente urbanas foi instaurado no município.

Agregado a esta situação, salienta-se a complexidade existente na interação mar-continente que sustenta o funcionamento dos sistemas ambientais litorâneos (RODRIGUEZ; CABO; BRESCANSIN, 1997). Desta forma, a constituição de um fluxo de matéria e energia oriundo da urbanização de Cubatão, acrescida da referida dinâmica secular, interfere na manutenção do equilíbrio deste sistema ambiental litorâneo ao modificar os seus componentes, implicando em impactos socioambientais subjacentes.

Neste contexto, surge a necessidade da formulação de estratégias para o delineamento de prognósticos dos problemas ambientais deste sistema, em uma visão holística têmporo-espacial, buscando compreender e adequar a relação dos elementos físicos perante os distintos graus de intervenção antrópica.

A concepção científica da Geoecologia da Paisagem responde a tal necessidade, já que permite $o$ desenvolvimento de uma análise ambiental integrada ao compreender "[...] um sistema de métodos, procedimentos e técnicas de investigação, cujo propósito consiste na obtenção de um conhecimento sobre o meio natural, com os quais se pode estabelecer um diagnóstico operacional" (RODRIGUEZ; SILVA; CAVALCANTI, 2004, p. 13).

Nesta concepção, a paisagem é entendida como um sistema de recursos, que "[...] lhe confere uma capacidade integrativa, para ser utilizada no processo de planejamento e organização ambiental" (RODRIGUEZ et al., 1995, p. 84). Ademais, considera-se que "[...] cada paisagem tem sua própria dinâmica funcional, que é sustentada por mecanismos e balanços de fluxos de EMI (Energia, Matéria e Informação) específicos e por uma cadeia de relações reversíveis (homeostáticas) que asseguram a integridade e coerência do sistema" (DIAKONOV, 1988 apud RODRIGUEZ;
SILVA; CAVALCANTI, 2004, p. 137).

Evidencia-se que qualquer alteração no funcionamento e nos mecanismos das relações de auto-regulação da dinâmica funcional desencadeia em desequilíbrios na mesma, resultando em uma dinâmica funcional degradante.

A degradação geoecológica, por sua vez, define-se como "[...] a perda de atributos e propriedades sistêmicas que garantem o cumprimento das funções geoecológicas e a atividade dos mecanismos de auto-regulação" (RODRIGUEZ; SILVA; CAVALCANTI, 2004, p. 137). É importante salientar que os processos geoecológicos degradantes se desenvolvem naturalmente ou são consequências do produto direto da ação antrópica.

A identificação dos processos degradantes e do nível de degradação possibilita reconhecer o estado geoambiental das paisagens. De acordo com Rodriguez, Silva e Cavalcanti (2004, p. 139), o estado geoambiental constitui-se como "[...] a situação geoecológica da paisagem dada, determinada pelo tipo e grau de impacto e a capacidade de reação e absorção dos geossistemas".

Assim, o presente artigo teve como objetivo discutir o diagnóstico do estado geoambiental das paisagens da área urbana do município de Cubatão (SP), executado a partir do uso da proposta metodológica de Rodriguez, Silva e Cavalcanti (2004), na escala 1:10.000. Este diagnóstico possibilita a identificação dos principais problemas ambientais existentes no cenário atual, fornecendo subsídios para a ordenação geoambiental da área de estudo.

\section{CARACTERIZAÇÃO DA ÁREA DE ESTUDO}

Aárea urbana do município de Cubatão (SP) localiza-se entre as coordenadas geográficas de $23^{\circ} 48^{\prime} 53^{\prime}$ "

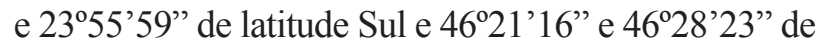
longitude Oeste, e abrange $79 \mathrm{~km}^{2}$ dos $148 \mathrm{~km}^{2}$ do território do município (Figura 1). Este município integra a subdivisão física e político-administrativa do litoral paulista denominada de Região Metropolitana da Baixada Santista (SÃO PAULO, 1996).

Em relação à divisão geomorfológica do Estado de São Paulo, o município de Cubatão se distribui na subzona da Serra do Mar e na zona das baixadas litorâneas, ambas situadas na Província Costeira (ALMEIDA, 1964). 
Figura 1. Localização da área urbana de Cubatão no Estado de São Paulo, Baixada Santista e Município (Sem escala).

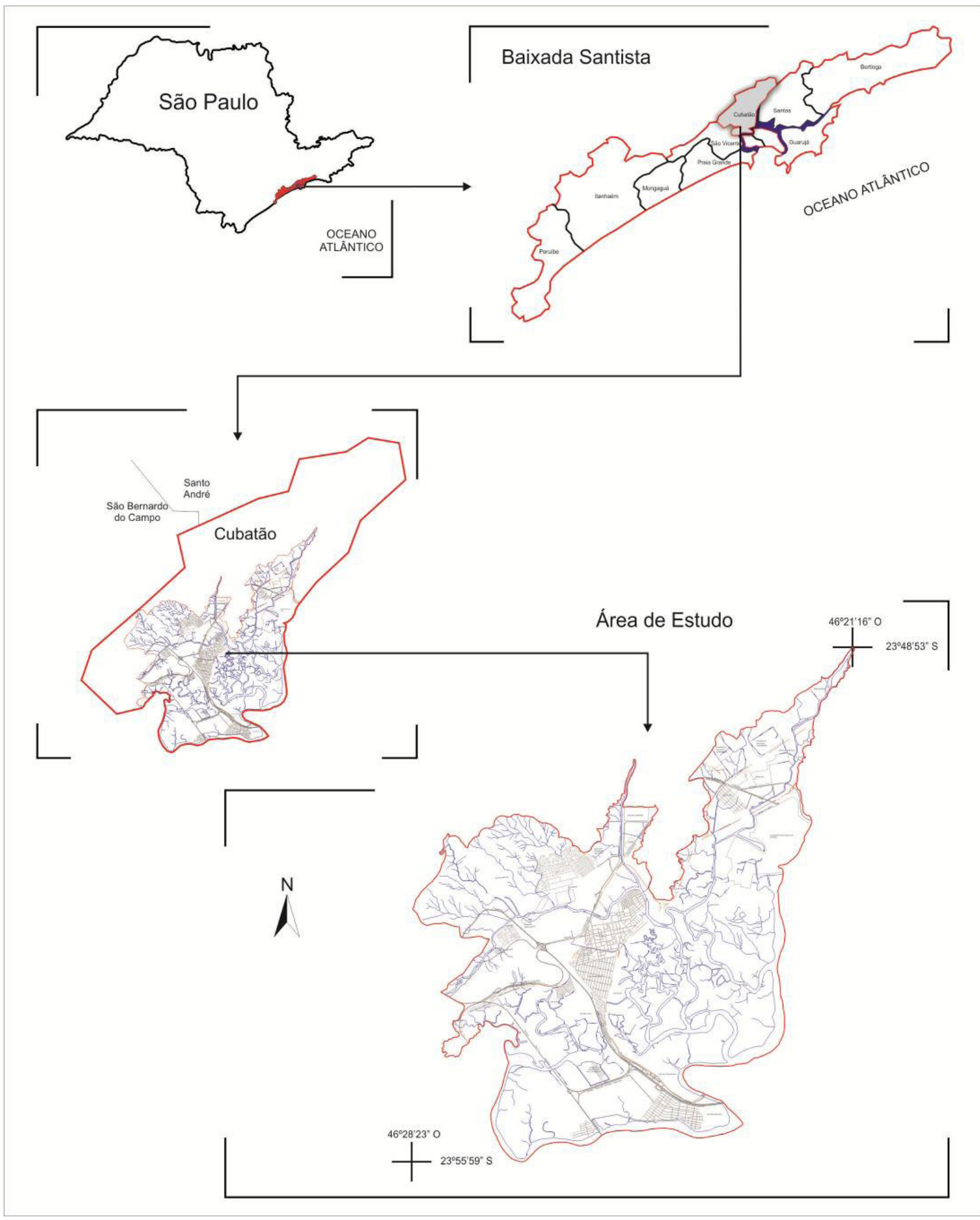

Elaboração dos autores. 
O clima do município abrange os regionais úmidos da face oriental e subtropical do continente, dominado por massa Tropical, os quais fazem parte dos climas zonais controlados por massas tropicais e polares (MONTEIRO, 1973). Em razão destas condições climáticas, acrescidas ainda do contexto geológico, geomorfológico e pedológico, encontravam-se no município de Cubatão as seguintes formações vegetais naturais: vegetação dos brejos de água doce; vegetação do mangue e vegetação da escarpa da Serra do Mar e dos morros (ANDRADE; LAMBERTI, 1965).

É importante salientar a degradação, no tempo e no espaço, das referidas formações vegetais, advinda da intervenção antrópica, a qual se vincula com a dinâmica de uso da terra da área de estudo. Em relação à dinâmica de uso da terra, ressalta-se que a ocupação urbana e industrial pressiona os referidos atributos naturais do município de Cubatão, repercutindo na definição da fragilidade ambiental. Consequentemente, a população residente se encontra sujeita aos impactos de ordem socioeconômica, assim como aos riscos ambientais diretos de deslizamentos e de poluição atmosférica e hídrica.

\section{MÉTODO E TÉCNICAS}

\section{Método}

A orientação metodológica do presente artigo teve respaldo nos princípios que concernem à Teoria Geral dos Sistemas aplicados à ciência geográfica através do critério funcional e do critério da complexidade estrutural, considerados os mais importantes para este tipo de análise (CHRISTOFOLETTI, 1979).

A escolha da área urbana do município de Cubatão (SP) como área de estudo justifica o uso da abordagem sistêmica quanto ao critério funcional, pois esse se constitui em um sistema aberto que recebe (input) e perde (output) energia e matéria. Quanto ao critério da complexidade estrutural, utilizou-se a concepção dos sistemas controlados, em que a atuação do homem "[...] pode intervir para produzir modificações na distribuição de matéria e energia dentro dos sistemas em sequência e, consequentemente, influenciar nas formas que com ele estão relacionadas" (CHRISTOFOLETTI, 1979, p. 19). No caso específico da área de estudo, acredita-se que as atividades antrópicas vêm rompendo com a capacidade de suporte deste sistema litorâneo.

Os princípios da Teoria Geral dos Sistemas se integram, ainda, a proposta metodológica de Rodriguez, Silva e Cavalcanti (2004). A execução desta proposta envolve as seguintes fases: organização; inventário; análise; diagnóstico; proposições e execução (Figura 2). Destas fases, aquela referente ao diagnóstico permite a caracterização do cenário atual, entendida como estado geoambiental, proporcionando a identificação dos principais problemas ambientais existentes. A análise do diagnóstico fornece subsídios à efetivação de um prognóstico ambiental e socioeconômico, possibilitando a realização de uma proposta de ordenamento geoambiental.

Esta análise é realizada a partir dos dados representados em documento cartográfico específico denominado de Carta de Estado Geoambiental da Área Urbana do Município de Cubatão (SP).

\section{Carta de Estado Geoambiental}

A carta de estado geoambiental indica a conjuntura dos componentes naturais da paisagem perante a capacidade de regulação de suas funções geoecológicas diante das intervenções antrópicas.

A elaboração deste material cartográfico se deu a partir da interpretação de Rodriguez, Silva e Cavalcanti (2004), considerando os procedimentos adotados por Amorim (2007) e adaptações realizadas segundo as peculiaridades da área urbana do município de Cubatão (SP).

Assim, a constituição deste material advém de uma análise correlativa das informações obtidas com os documentos cartográficos elaborados para a caracterização dos componentes antrópicos (Cartas de Uso da Terra dos cenários de 1962 e 2007) e naturais (Carta de Declividade; Carta Geomorfológica; Representação Cartográfica dos Dados Litológicos; Cartas da Rede Hidrográfica) da área de estudo, em que o uso da terra, pautado nas restrições legais, torna-se elemento preponderante na definição do Estado Geoambiental.

Em relação ao Estado Geoambiental, esse pode ser classificado em: 
- Estável (não alterado): conserva-se a estrutura original. Não existem problemas ambientais significativos que deteriorem a paisagem. O nível dos processos geoecológicos tem um caráter natural. A influência antropogênica é muito pequena; - Medianamente estável (sustentável): refletem poucas mudanças na estrutura. Incidem alguns problemas de intensidade leve a moderada, que não alteram o potencial natural e a integridade do geossistema. Constituem áreas que são desenvolvidas e utilizadas pelo homem, de tal forma, que o uso da terra está balanceado com o potencial e pode ser sustentado por várias gerações. Estas áreas necessitam de uma manutenção de baixo custo e um cuidado para assegurar que continue a sustentabilidade; - Instável (insustentável): fortes mudanças da estrutura espacial e funcional, de tal maneira que não consegue cumprir as funções ecológicas, porém parte do geossistema conserva a integridade. A incidência de alguns problemas ambientais resultantes da sobreexploração dos recursos dá lugar a um declínio na produtividade e que essa provavelmente se perca no curso de uma geração; - Crítico: perda parcial da estrutura espacial e funcional com eliminação paulatina das funções ecológicas. Manifesta um número significativo de problemas ambientais de forte intensidade. São áreas que o uso da terra e o impacto humano excederam à capacidade de suporte dos geossistemas, o que resulta em uma drástica redução do potencial da terra. As paisagens que estão nesse estado necessitam da aplicação de medidas de mitigação urgentes e imediatas para recuperar o potencial natural. A mitigação dos processos geoecológicos levará pelo menos uma geração e será muito cara; - Muito crítico: perda e alteração generalizada da estrutura espacial e funcional. O geossistema não está em condições de cumprir as funções geoecológicas. Experimentam a atividade de um número significativo de problemas ambientais de intensidade muito forte. $\mathrm{O}$ potencial inicial de recursos foi completamente destruído. Não são áreas adequadas para o uso humano. A população necessita ser realocada, o que implica enormes custos (MATEO; MARTINEZ, 1998; GLAZOVSKIY et al., 1998 apud RODRIGUEZ; SILVA; CAVALCANTI, 2004, p. 139-141). 
Figura 2. Fluxograma das etapas de efetivação da metodologia proposta por Rodriguez, Silva e Cavalcanti (2004).

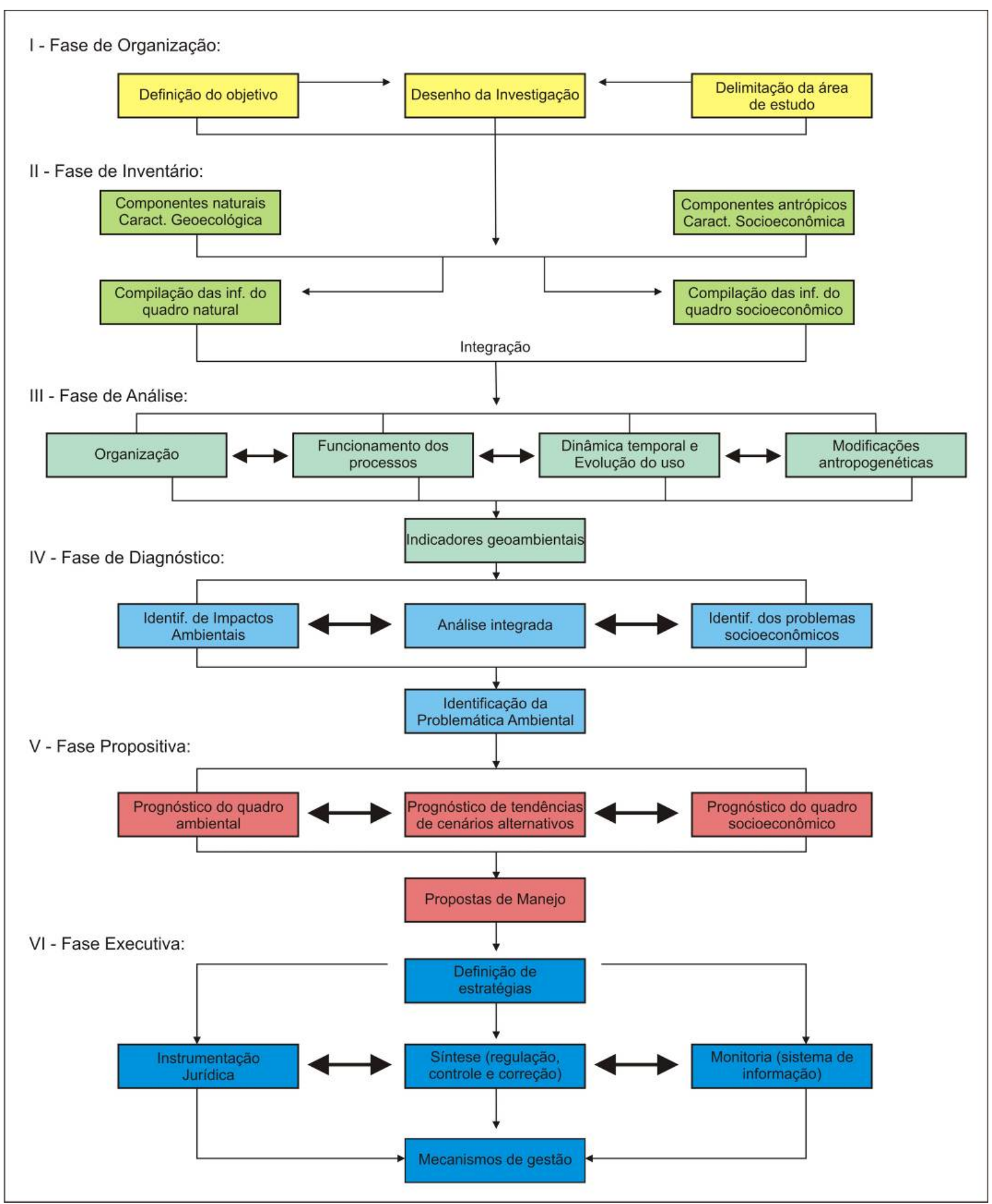

Fonte: RODRIGUEZ; SILVA; CAVALCANTI, 2004. 
$\mathrm{Na}$ área de estudo, as paisagens classificadas com o Estado Geoambiental Estável correspondem àquelas identificadas em grande parte do Parque Estadual da Serra do Mar, Morro Mazagão e Morros Isolados, bem como ainda nas áreas em que os manguezais e a restinga mantinham a composição original. As paisagens com Estado Medianamente Estável não foram identificadas na área de estudo. Já as paisagens com o Estado Instável envolvem aquelas com cobertura rasteira e uso indefinido que não se encontram em Áreas de Preservação Permanente (APPs). Nestas situações não se verifica uma transgressão na legislação ambiental, mas há mudanças nos atributos físicos das paisagens que comprometem o cumprimento de suas funções ecológicas.

As paisagens com o Estado Geoambiental Crítico abrangem aquelas em que o uso da terra se encontrava relacionado ao urbano e as áreas com cobertura rasteira e uso indefinido. Estes tipos de uso, além de transgredir a legislação ambiental, proporcionam dano parcial sobre as funções ecológicas das paisagens, mas essas ainda são passíveis de reabilitação em longo prazo. Acredita-se que a reabilitação destas paisagens pode ser desenvolvida por meio do estabelecimento de um novo equilíbrio entre os elementos antrópicos e naturais, que não implique em problemas ambientais a população local.

Por fim, o Estado Geoambiental Muito Crítico foi apontado para a área ocupada por mineração, a qual denota uma perda integral das funcionalidades dos elementos naturais que compõem a paisagem.

\section{ANÁLISE DOS RESULTADOS}

A análise da carta de Estado Geoambiental da área urbana do município de Cubatão-SP (Figura 3) foi desenvolvida a partir da consideração dos limites das feições geomorfológicas que compreendem as paisagens da subzona da Serra do Mar e da baixada litorânea (Figura 4).

As paisagens da subzona da Serra do Mar, equivalentes ao Parque Estadual da Serra do Mar, localizado no extremo noroeste da área de estudo e, ainda, aos morros isolados, foram classificadas, predominantemente, com um Estado Geoambiental Estável.

A principal razão para a definição desta classe foi a manutenção da composição original da vegetação de Mata Atlântica, a qual se constitui como compatível nestas paisagens, ou seja, compreende as "áreas em que a função socioeconômica está dentro da capacidade de uso potencial da unidade física, o que representa uma alteração com níveis de impactos negativos completamente controláveis" (OLIVEIRA, 2003, p. 75).

Ademais, este tipo de uso é adequado, pois não transgride a legislação ambiental que abrange estas paisagens (OLIVEIRA, 2003) - decreto 10.251 de 30/08/77, que define a partir da cota de 100 metros, a área referente ao Parque Estadual da Serra do Mar (SÃO PAULO, 1977); e Lei Complementar $n^{\circ} .2 .513$ de 10/09/1998 (CUBATÃO, 1998), que protege os distintos morros isolados dispersos na área de estudo. 
Figura 3 - Carta de Estado Geoambiental da área urbana do município de Cubatão (SP).

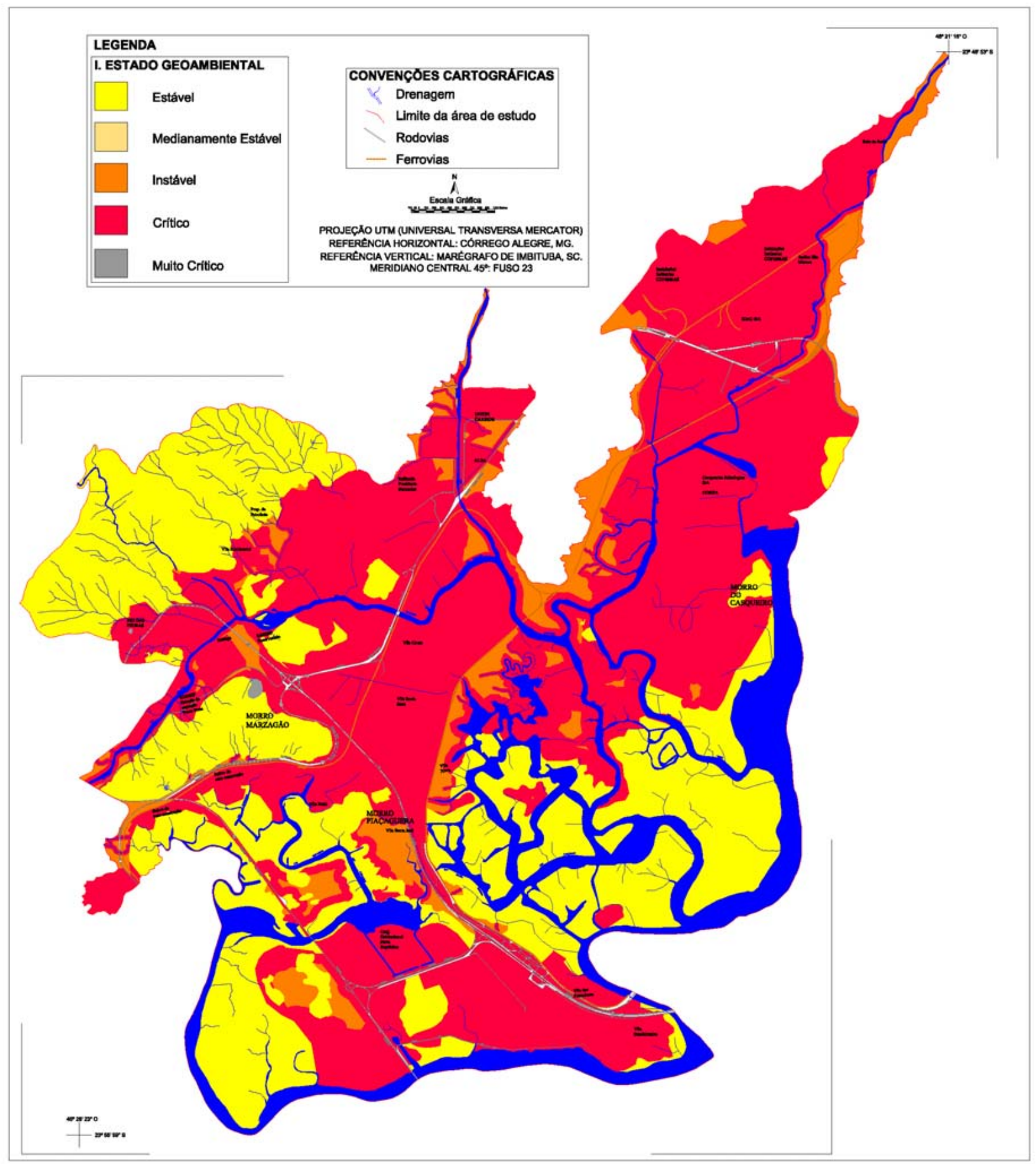

Elaboração dos Autores. 
Figura 4. Limites das feições geomorfológicas para análise das paisagens da subzona da Serra do Mar e da baixada litorânea.

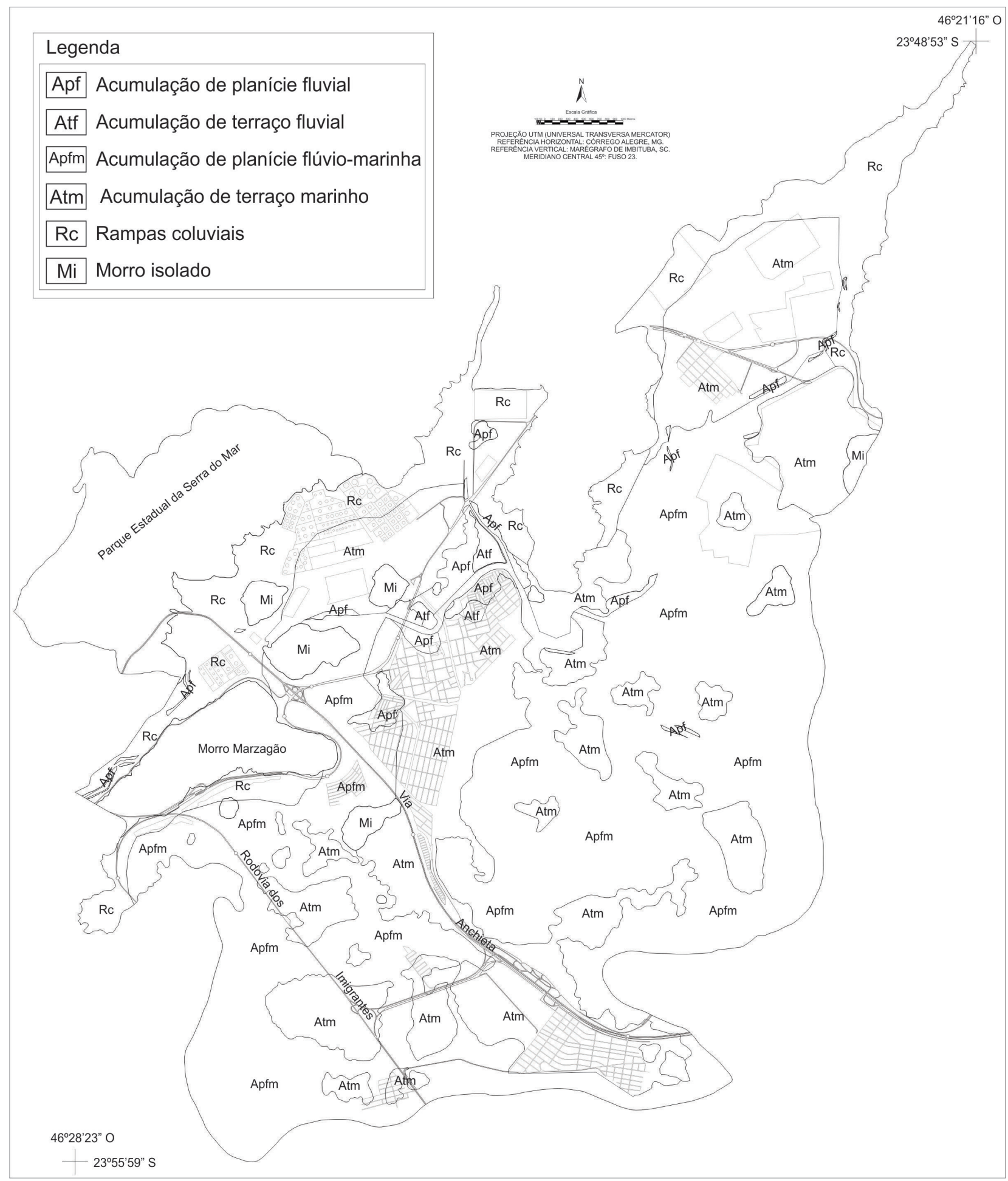

Elaboração dos autores. 
Neste contexto, nota-se que não há uma problemática ambiental no interior das referidas paisagens, mas essas possuem um potencial de instabilidade natural que pode acarretar no desencadeamento de movimentos de massa e consequente exposição da população às possibilidades da ocorrência de situações de risco.

A maior mobilidade no transporte de detritos superficiais nestas paisagens se desenvolve nas áreas caracterizadas pela presença de vertentes retilíneas, as quais se encontram próximas as linhas de cumeadas, em específico, nos trechos com declive igual e superior a $45 \%$ e solo menos espesso. Ademais, acredita-se que tais movimentos sejam dinamizados em razão da desestabilização das vertentes advinda da pressão exercida pelas atividades antrópicas localizadas nos sopés destas paisagens.

Ressalta-se a constatação do uso urbano em trechos das médias e baixas vertentes do Parque Estadual da Serra do Mar e do Morro Mazagão, ambos localizados no noroeste da área de estudo. As estruturas deste tipo de uso assinalam os atuais indícios de perturbação na topografia local do Sistema Serrano. A partir desta situação, as referidas áreas são distinguidas na carta de Estado Geoambiental da área urbana do município de Cubatão (SP) com um Estado Geoambiental Crítico, que implica na existência de problemas ambientais advindos da transgressão a legislação ambiental e pressão sobre os seus atributos físicos. Esta problemática insere tais paisagens ao risco de dinamização dos movimentos de massa e provável assoreamento das drenagens a jusante.

Nestas paisagens ainda foram identificadas antigas áreas de mineração, classificadas com o Estado Geoambiental Muito Crítico, já que nesta situação há o comprometimento das estruturas litosféricas e, portanto, impossibilidade de recuperação.

No que tange ainda às feições do uso urbano, é importante salientar a constatação da evolução da mancha urbana sobre a área de estudo, resultando na introdução de novas intervenções antrópicas que dão origem às morfologias antropogênicas.
A figura 5 aponta a variação espacial e a distribuição, em porcentagem (\%), da área das classes de uso da terra área urbana e área de expansão urbana no período de 1962 a 2007 e, ainda, apresenta trechos das paisagens das médias e baixas vertentes do Parque Estadual da Serra do Mar e do Morro Mazagão, nas quais há considerável presença de estruturas de uso urbano.

Além disso, a correlação destes dados com os limites das feições geomorfológicas utilizadas para análise das paisagens das duas zonas da Província Costeira mostra a maior expressividade do uso urbano na baixada litorânea, resultando no predomínio da classe de Estado Geoambiental Crítico. O prevalecimento desta classe é determinado ao considerar que o uso urbano corrompe as características naturais das paisagens que compõem tal zona, assinaladas com elevado nível de fragilidade e, ainda, viola a legislação ambiental.

A mencionada fragilidade advém da existência de formas de acumulação geradas por agentes morfogenéticos diferenciados - verificam-se paisagens vinculadas à ação das águas fluviais, à ação marinha, assim como à ação combinada destes dois agentes no caso das acumulações fluvio-marinhas.

Ressalta-se que estas formas de acumulação são compostas por litologias sedimentares, datadas do Quaternário, em que tal substrato sedimentar possibilitou a similaridade nas características de declives, quantificados em valores inferiores a $2 \%$, com exceção das paisagens das Rampas Coluviais, as quais apresentaram declives de $2 \%$ à superiores a $45 \%$, com maior expressão daqueles com valores entre 2 a $5 \%$.

A associação das características morfogenéticas aos diversos níveis topográficos existentes, acrescidas da dinâmica quente e úmida do clima atual, implica em amplas possibilidades de remobilização do material sedimentar. Além destes aspectos, salienta-se a gradativa redução da vegetação original das distintas paisagens que compõem a baixada litorânea, especialmente a degradação da restinga e do mangue. 
Figura 5 - Variação espacial e a distribuição, em porcentagem (\%), da área das classes de uso da terra área urbana e área de expansão urbana no período de 1962 a 2007 e, ainda, os trechos de unidades do Sistema Serrano em que há considerável presença de estruturas atuais do uso urbano.

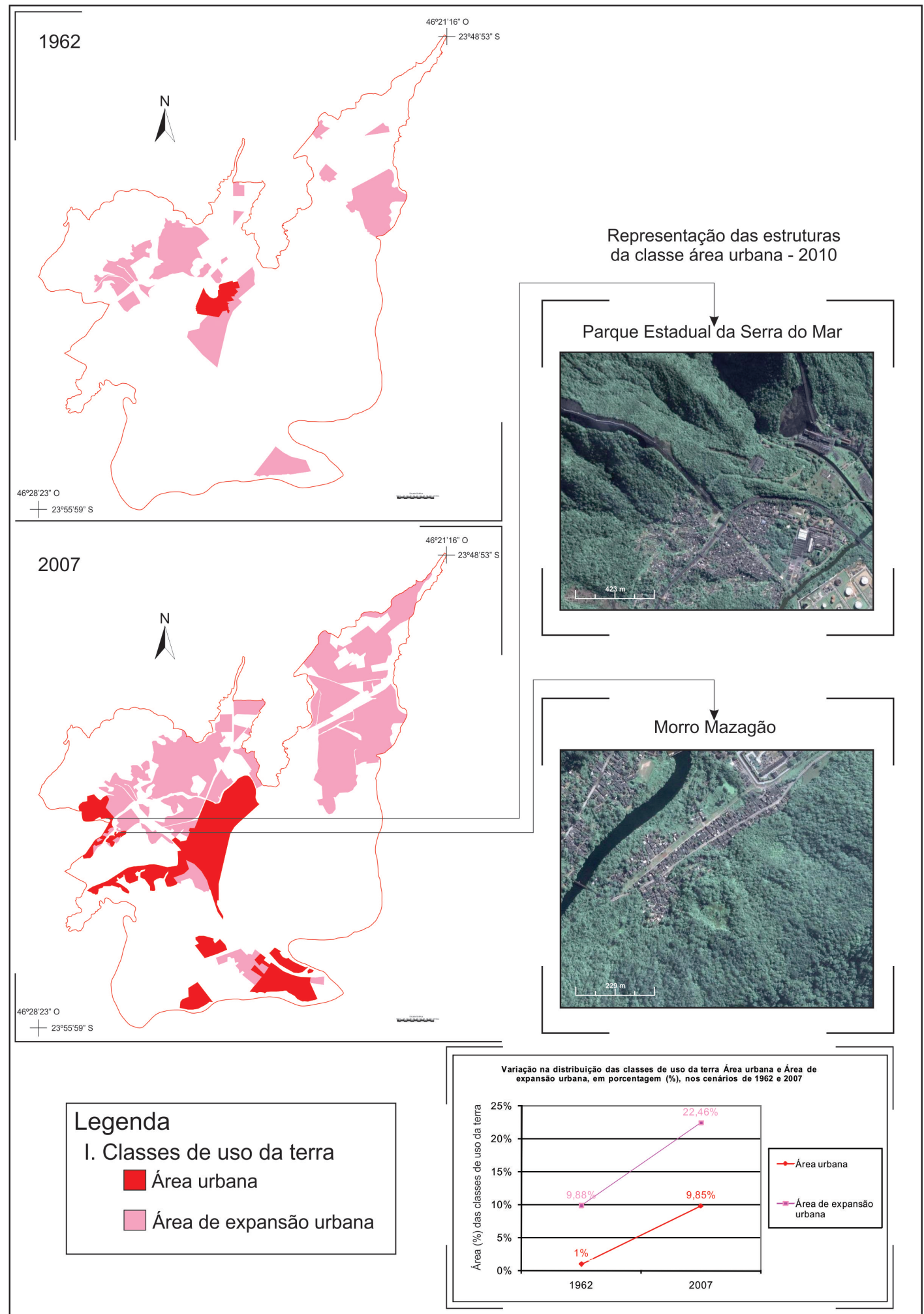

Fonte: Google Earth ${ }^{\mathrm{TM}}$, 2010, adaptado e organizado pelos autores. 
A consolidação do uso urbano em terraços marinhos acarretou em problemas ambientais relacionados à impermeabilização do solo e a transgressão do inciso I do Artigo 4o da Lei no 12.651 de 25/05/2012 Código Florestal (BRASIL, 2012), que define as APPs, situadas nas faixas marginais de qualquer curso d'água natural perene e intermitente, excluídos os efêmeros, desde a borda da calha do leito regular. Na carta de Estado Geoambiental da área urbana do município de Cubatão (SP), tais feições são envolvidas pelo Estado Geoambiental Crítico. É importante salientar o risco relacionado ao aumento de enchentes e desequilíbrios morfogenéticos, caso seja mantida a retirada da vegetação natural e expansão destas atividades antrópicas.

Além do uso urbano, alguns trechos destas paisagens eram recobertos por cobertura rasteira e uso indefinido. Esta constatação se dava no exterior das APPs, levando a definição de um Estado Geoambiental Instável, pois ocorre a alteração dos atributos naturais, mas não há a violação da legislação ambiental. Esta configuração é identificada nos terraços marinhos localizados na porção central e sudoeste da área de estudo.

As paisagens compostas por formas de acumulação em terraço marinho localizadas no extremo sudeste são exceção ao contexto descrito, já que a manutenção da vegetação natural de restinga culminou no estabelecimento da classe Estável no documento cartográfico correspondente ao Estado Geoambiental.

As estruturas de uso urbano também foram consolidadas sobre as paisagens que abrangem as formas de acumulação de terraço fluvial, localizadas nas margens esquerda e direita do rio Cubatão, bem como na margem direita do rio Perequê, em área próxima a confluência destes rios. A presença de atividades antrópicas sobre estes terraços pode contribuir para o desequilíbrio erosivo/deposicional das drenagens no cenário atual. Assim, torna-se possível uma maior liberação de sedimentos para os cursos fluviais, implicando no assoreamento dos mesmos e dinamização das enchentes no local. Ademais, as feições urbanas transgridem as APPs ao longo das margens dos rios, definidas segundo o Código Florestal (BRASIL, 2012).

Nesta situação, tais paisagens foram classificadas com um Estado Geoambiental Crítico. Há ainda, na confluência dos rios Cubatão e Perequê, espaços recobertos por gramíneas no interior das áreas com uso urbano, resultando na definição do Estado Geoambiental Instável.

Nas planícies flúvio-marinhas foram constatadas modificações em suas estruturas a partir do uso urbano, cujo fato possibilitou a constituição de morfologias antropogênicas. As referidas modificações se encontram relacionadas à construção de aterros e intervenções nos cursos d'água a fim de drenar as planícies flúvio-marinhas.

Neste contexto, verifica-se a ocupação das áreas de manguezais, cuja situação representa uma transgressão a legislação ambiental, já que a área recoberta por manguezal, em toda a sua extensão, é definida como APPs no inciso VII do Artigo 4o do Código Florestal (BRASIL, 2012). Ademais, a área de manguezal se encontra protegida por legislação local (CUBATÃO, 1998).

O uso urbano também corrompe o equilíbrio destas paisagens, tornando-as sujeitas a maior remobilização de material e desequilíbrios erosivos/ deposicionais. Ao considerar tal conjuntura, estas paisagens foram classificadas com o Estado Geoambiental Crítico.

A figura 6 ilustra trecho de uma paisagem composta por planície flúvio-marinha, assinalada com ocupação irregular que exerce pressão sobre a vegetação de mangue, destacando ainda as estruturas atuais do uso urbano e os limites das formas de relevo circundantes. 
Figura 6. Ocupação irregular em paisagem composta por Planície Flúvio-Marinha, localizada nas proximidades do sopé do morro Mazagão.

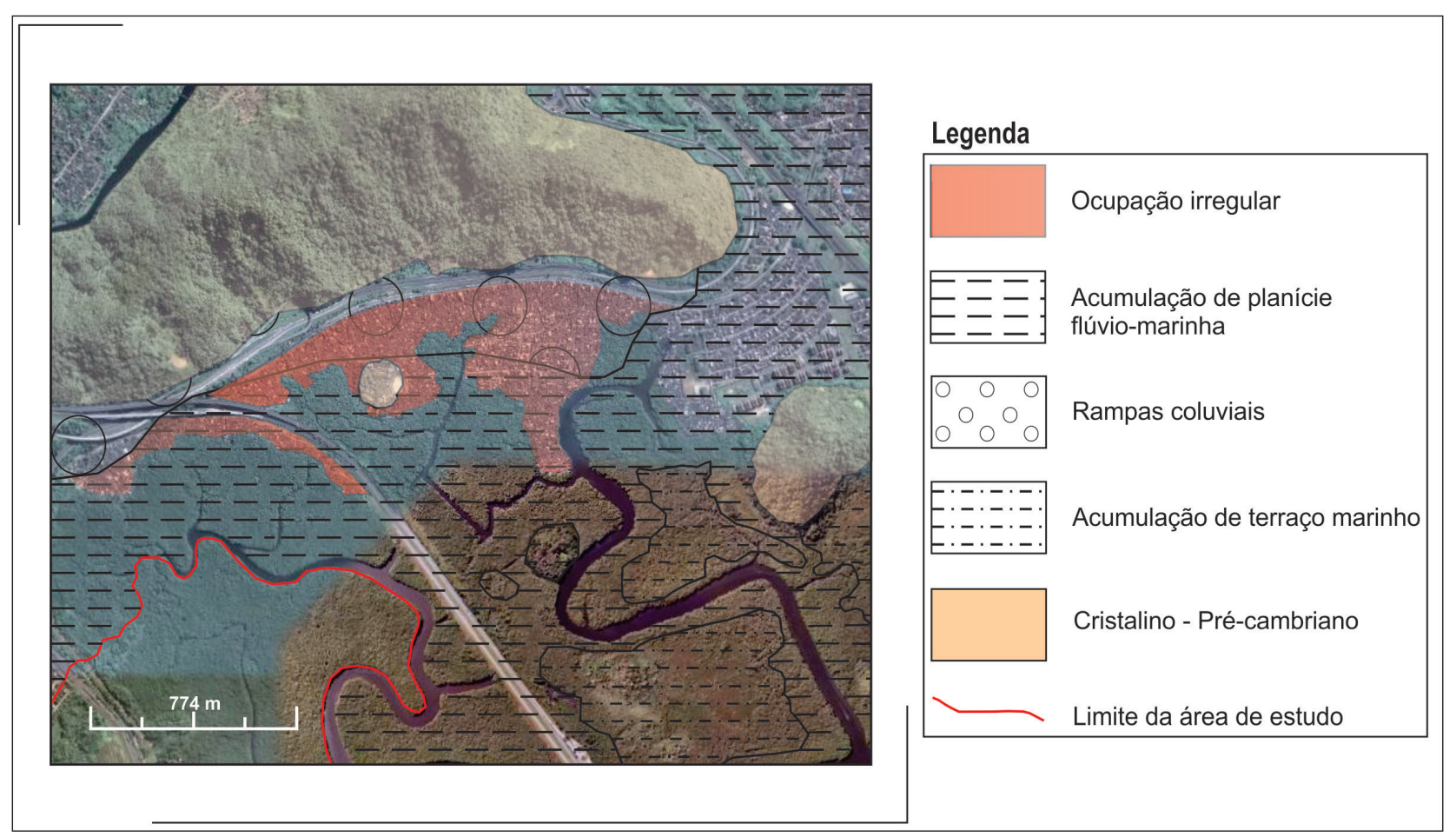

Fonte: Google Earth ${ }^{\mathrm{TM}}$, 2010, adaptado e organizado pelos autores.

As paisagens compostas por formas de acumulação de planície flúvio-marinha, localizadas no extremo sudeste e sudoeste da área de estudo são exceções ao contexto descrito, pois essas se mantêm cobertas por mangue. Assim, considera-se que essas não apresentam problemas vinculados à violação da legislação ambiental e modificações em seus atributos naturais, sendo evidenciadas na carta de Estado Geoambiental pela presença da classe Estável.

Em relação às paisagens sustentadas por formas de acumulação de planícies fluviais, evidencia-se que a consolidação do modelo urbano sobre as mesmas e, ainda, a existência de trechos caracterizados por abandono de atividades agrícolas, configuram a definição do Estado Geoambiental Crítico.

Assim, verifica-se uma problemática ambiental vinculada à violação das APPs situadas em faixa marginal ao longo dos cursos d'água, definidas pelo Código Florestal (BRASIL, 2012), bem como a alteração das características físicas destas paisagens. Há ainda o risco de enchentes e desequilíbrios morfogenéticos locais caso ocorra o aumento da impermeabilização do solo.
Por fim, ressalta-se que as formas de acumulação em rampas coluviais, localizadas nos sopés das paisagens da subzona da Serra do Mar, também se encontram marcadas por estruturas do uso urbano. Cabe salientar que o substrato dessas é composto por sedimentos advindos de deslizamentos do Sistema Serrano, fato que implica na instabilidade do terreno, já que há uma deposição frequente de detritos . Além disso, estas paisagens são drenadas por canais fluviais, que se encontram resguardados pelas APPs situadas em faixa marginal, de acordo com a largura dos cursos d'água (BRASIL, 2012).

A partir deste contexto, configura-se o Estado Geoambiental Crítico nos locais com uso urbano em APPs. Os trechos destas paisagens recobertos por uso indefinido e cobertura rasteira no exterior das APPs possuem o Estado Geoambiental Instável, já que tais usos não transgridem a legislação ambiental, mas também não mantêm a estabilidade dos terrenos.

A problemática ambiental é evidente, já que a impermeabilização do solo e consequente aumento no escoamento superficial compromete o sistema de drenagem. É necessário ainda se atentar ao risco 
eminente nestas rampas coluviais, vinculado à possibilidade de dinamização de movimentos de massa, caso a pressão antrópica se mantenha, desestabilizando as vertentes das paisagens da Serra do Cubatão e do Morro Mazagão.

\section{CONSIDERAÇÕES FINAIS}

A Carta de Estado Geoambiental da área urbana do município de Cubatão (SP) se constitui como documento de extrema valia para o planejamento ambiental da área, já que essa fornece dados sobre a capacidade de regulação das funções geoecológicas das paisagens segundo o grau de intervenção antrópica em seus componentes naturais. Ademais, ressalta-se que este documento revela os conflitos do uso da terra atual com a legislação ambiental.

As paisagens inseridas na subzona da Serra do Mar foram classificadas, predominantemente, com um Estado Geoambiental Estável, evidenciando a manutenção da composição original da vegetação de Mata Atlântica e, consequente adequação à legislação ambiental. Há ressalvas nesta subzona, já que a presença do uso urbano e da mineração em trechos das médias e baixas vertentes corrompe os atributos físicos e transgride a legislação ambiental, resultando na definição das classes de Estado Geoambiental Crítico e Muito Crítico. Nesta situação, há o risco de dinamização da instabilidade natural dessas paisagens, culminando no aumento dos movimentos de massa.

Em relação ainda ao uso urbano, evidencia-se que esse compreende com maior expressividade as paisagens da baixada litorânea, caracterizadas por elevada fragilidade natural. Assim, tal uso é responsável pela pressão nos elementos naturais e violação na legislação ambiental, fato que implica no predomínio de paisagens com o Estado Geoambiental Crítico.

As paisagens compostas por formas de acumulação em terraço marinho e planície flúvio-marinha são aquelas em que a pressão do referido uso se desenvolve com maior intensidade. As modificações em seus atributos naturais se encontram associadas à impermeabilização do solo e consequente aumento no número de inundações e desequilíbrios morfogenéticos.

É importante salientar que há paisagens na baixada litorânea que se distanciam deste contexto, já que a manutenção da vegetação original de mangue em trechos das planícies flúvio-marinha e de restinga nos terraços marinhos resultou na definição do Estado Geoambiental Estável.

Por fim, ressalta-se que os dados obtidos no diagnóstico do estado geoambiental fornecem subsídios para a elaboração de propostas de zoneamento geoambiental, já que este tipo de modelo territorial objetiva o aproveitamento sustentável dos recursos e a proteção das paisagens.

\section{AGRADECIMENTOS}

Agradecimentos pelo financiamento à Fundação de Amparo à Pesquisa do Estado de São Paulo - FAPESP - Processo n ${ }^{\circ} .:$ 08/57005-6.

\section{REFERÊNCIAS}

ALMEIDA, F. F. M. de. Fundamentos geológicos do relevo paulista. Boletim IGC, São Paulo, n. 41, p. 167-262, 1964.

AMORIM, R. R. Análise geoambiental com ênfase aos setores de encosta da área urbana do município de São Vicente-SP. 2007. 207f. Dissertação (Mestrado em Análise Ambiental e Dinâmica Territorial) - Instituto de Geociências, Universidade de Campinas, Campinas, 2007.

ANDRADE, M. A. B. de; LAMBERTI, A. A vegetação. In: AZEVEDO, A. (Org.). A Baixada Santista: aspectos geográficos, V. I - As bases físicas. São Paulo: Edusp, p. 151-178, 1965.

BRASIL. Lei n ${ }^{\circ} 12.651$ (Código Florestal), de 25 de maio de 2012. Dispõe sobre a proteção da vegetação nativa e dá outras providências. Diário Oficial [da] República Federativa do Brasil, Brasília, DF, 25 mai 2012. Disponível em: <http://www.planalto.gov.br/ ccivil_03/_Ato2011-2014/2012/Lei/L12651.htm>. Acesso em: 6 fev. 2014.

CHRISTOFOLETTI, A. Análise de sistemas em Geografia. São Paulo: Hucitec, 1979. 
CUBATÃO (Prefeitura Municipal). Lei Complementar $n^{\circ}$. 2.513, de 10 de setembro de 1998. Institui normas sobre o Parcelamento, Uso e Ocupação do Solo do Município de Cubatão, e dá outras providências. 15 set 1998. Disponível em: <http://www.novomilenio. inf.br/cubatao/pdir04.htm>. Acesso em: 6 fev. 2014.

MONTEIRO, C. A. de F. A dinâmica climática e as chuvas no Estado de São Paulo - estudo geográfico sob forma de atlas. São Paulo: Instituto de Geografia, Universidade de São Paulo, 1973.

OLIVEIRA, R. C. Zoneamento ambiental como subsídio para o planejamento de uso e ocupação do solo do municipio de Corumbatai-SP. 2003. $141 \mathrm{f}$. Tese (Doutorado em Geociências) - IGCE, Universidade Estadual Paulista, Rio Claro, 2003.

RODRIGUEZ, J. M. M. et al. Análise da paisagem como base para uma estratégia de organização geoambiental: Corumbataí (SP). Geografia, Rio Claro, v.20, n.1, p.81-129, 1995.

RODRIGUEZ, J. M. M.; CABO, A. R. de.; BRESCANSIN, R. B. Laudos periciais e pareceres técnicos em áreas litorâneas. In: MAURO, C. A. de (Coord.). Laudos periciais em depredações ambientais. Rio Claro: LPM/ Deplan, IGCE, UNESP, p.177-214, 1997.
RODRIGUEZ, J. M. M.; SILVA, E. V. da.; CAVALCANTI, A. P. B. Geoecologia das Paisagens: uma visão geossistêmica da análise ambiental. Fortaleza: UFC, 2004.

SÃO PAULO (Estado). Decreto $n^{\circ} 10.251$, de 30 de agosto de 1977. Cria o Parque Estadual da Serra do Mar e dá providências correlatas. Disponível em: $<$ http://www.al.sp.gov.br/repositorio/legislacao/decreto/1977/decreto-10251-0.08.1977.html>. Acesso em: 6 fev. 2014.

SÃO PAULO (Estado). Lei Complementar Estadual ${ }^{\circ}$ 815, de 30 de julho de 1996. Cria a Região Metropolitana da Baixada Santista e autoriza o Poder Executivo a instituir o Conselho de Desenvolvimento da Região Metropolitana da Baixada Santista, a criar entidade autárquica a construir o Fundo de Desenvolvimento Metropolitano da Baixada Santista, e dá Providências correlatas. Disponível em: <http://www.agem.sp.gov. br/pdf/Lei\%20Complementar\%20Estadual\%20 n\%C2\%BA\%20815.pdf>. Acesso em: 6 fev. 2014. 